\title{
Risk perception during the 2014-2015 Ebola outbreak in Sierra Leone
}

\author{
Maike Winters $^{1^{*}}$ (D), Mohamed F. Jalloh ${ }^{1,2}$, Paul Sengeh ${ }^{3}$, Mohammad B. Jalloh ${ }^{3}$, Zangin Zeebari ${ }^{4}$ and \\ Helena Nordenstedt ${ }^{1}$
}

\begin{abstract}
Background: Perceived susceptibility to a disease threat (risk perception) can influence protective behaviour. This study aims to determine how exposure to information sources, knowledge and behaviours potentially influenced risk perceptions during the 2014-2015 Ebola Virus Disease outbreak in Sierra Leone.

Methods: The study is based on three cross-sectional, national surveys (August 2014, $n=1413$; October 2014, $n=$ 2086; December 2014, $n=3540$ ) that measured Ebola-related knowledge, attitudes, and practices in Sierra Leone. Data were pooled and composite variables were created for knowledge, misconceptions and three Ebola-specific behaviours. Risk perception was measured using a Likert-item and dichotomised into 'no risk perception' and 'some risk perception'. Exposure to five information sources was dichotomised into a binary variable for exposed and unexposed. Multilevel logistic regression models were fitted to examine various associations.

Results: Exposure to new media (e.g. internet) and community-level information sources (e.g. religious leaders) were positively associated with expressing risk perception. Ebola-specific knowledge and hand washing were positively associated with expressing risk perception (Adjusted OR [AOR] 1.4, 95\% Confidence Interval [CI] 1.2-1.8 and AOR 1.4, 95\% Cl 1.1-1.7 respectively), whereas misconceptions and avoiding burials were negatively associated with risk perception, (AOR 0.7, 95\% Cl 0.6-0.8 and AOR 0.8, 95\% Cl 06-1.0, respectively).

Conclusions: Our results illustrate the complexity of how individuals perceived their Ebola acquisition risk based on the way they received information, what they knew about Ebola, and actions they took to protect themselves. Community-level information sources may help to align the public's perceived risk with their actual epidemiological risk. As part of global health security efforts, increased investments are needed for community-level engagements that allow for two-way communication during health emergencies.
\end{abstract}

Keywords: Risk perception, Infectious diseases, Epidemiology, Global health, Ebola, Epidemic

\section{Background}

In a small remote village in Guinea in December 2013, an 18-month-old boy suddenly became very ill and died [1]. The virus that killed him was later confirmed to be Ebola. In a few months, the outbreak spread to neighbouring Liberia and Sierra Leone [2]. The Ebola outbreak had

\footnotetext{
* Correspondence: Maike.winters@ki.se

'Department of Global Public Health, Karolinska Institutet, Tomtebodavägen 18A, 17717 Stockholm, Sweden

Full list of author information is available at the end of the article
}

already spread to the capital cities of all three affected countries by the time the World Health Organization declared it a Public Health Emergency of International Concern in August 2014 [2]. It took more than 2 years to stop the Ebola outbreak in West Africa. In the three most heavily affected countries, more than 28,000 people became infected, of which more than 11,000 died [3].

Fear, worry and perception of Ebola risk spread across the globe despite the majority of cases occurring in West Africa. People in countries far away from the actual

C C The Author(s). 2020 Open Access This article is licensed under a Creative Commons Attribution 4.0 International License, which permits use, sharing, adaptation, distribution and reproduction in any medium or format, as long as you give appropriate credit to the original author(s) and the source, provide a link to the Creative Commons licence, and indicate if changes were made. The images or other third party material in this article are included in the article's Creative Commons licence, unless indicated otherwise in a credit line to the material. If material is not included in the article's Creative Commons licence and your intended use is not permitted by statutory regulation or exceeds the permitted use, you will need to obtain permission directly from the copyright holder. To view a copy of this licence, visit http://creativecommons.org/licenses/by/4.0/. The Creative Commons Public Domain Dedication waiver (http://creativecommons.org/publicdomain/zero/1.0/) applies to the data made available in this article, unless otherwise stated in a credit line to the data. 
epidemic reportedly felt at risk of getting Ebola $[4,5]$. The few Ebola cases that occurred in Europe and the United States might have exacerbated the risk perception in places where there was virtually no transmission risk [2]. On the other hand, in Ghana, closer to the actual epicentre of the Ebola epidemic, a majority of $62 \%$ of survey respondents in the Greater Accra Region reported that they did not feel at risk of contracting Ebola [6].

In Sierra Leone, the country with the largest number of Ebola cases, risk perception was expectedly elevated, with $58 \%$ of survey respondents reporting that they felt at-risk of contracting Ebola in August 2014-just 3 months from the declaration of the country's Ebola outbreak [7]. A different survey conducted in March 2015 in Sierra Leone, several months after the peak of the outbreak, found that $90 \%$ of respondents felt that they were at-risk of contracting Ebola [8].

Risk perception is defined as "people's subjective judgments about the likelihood of negative occurrences such as an injury, illness, disease and death" [9]. According to the psychometric paradigm, risk perception depends on a wide range of characteristics of that risk [10]. For instance, risks that are not controllable, have catastrophic potential, are certain to be fatal, and where the effects are immediate and not known to science, are more likely to be perceived as more dangerous [10]. The Ebola outbreak ticked all of those boxes.

Worldwide fears of an Ebola pandemic were likely further fuelled by non-stop media coverage of the outbreak [11]. The media's role in the perception of risk is highlighted in the Social Amplification of Risk Framework [12]. This framework states that social, psychological and cultural processes all have the potential to heighten or to attenuate the perceived risk. An especially important role in this framework is assigned to communication, both through interpersonal communication and through the news media. The media generally favours 'newsworthy stories' that are new, unusual or dramatic, thereby potentially amplifying the perceived risk [12]. A survey in Germany showed that people who increased their media use to keep informed about Ebola were more likely to feel worried about the outbreak [5]. An analysis of news coverage of the Ebola outbreak in the United States found that $96 \%$ of the analysed news stories contained at least one risk-elevating message, whereas $55 \%$ of the news stories contained at least one risk-minimizing message [11].

In a situation like the Ebola epidemic or the ongoing covid-19 pandemic, large-scale behaviour change of the public is needed to curb the outbreak [13]. In many West African communities, people needed to stop traditional burial practices such as washing and touching corpses, as this formed an important risk of Ebola infection [14]. Risk communication and social mobilization interventions aimed to inform and engage the public to elicit the desired behavioural change. Previous research in Sierra Leone found that exposure to information sources was associated with increased Ebola-specific knowledge and protective behaviours [15]. Risk perception is thought to be an important determinant of behaviour change [16, 17]. According to WHO's risk communication guidelines, 'risk perception is the primary predictor for disaster prevention and mitigation behaviours' [17]. Behaviour change models such as the Health Belief Model point to the importance of risk perception in influencing behaviour change [18]. Vice versa, risk perception can in turn be influenced by behaviour change, as put forward in the risk reappraisal hypothesis [19].

Not much is known about the determinants of risk perception and how knowledge and behaviours influence risk perception. Therefore, this study aims to investigate the association between exposure to information sources and risk perception in the Ebola outbreak in Sierra Leone. Furthermore, it investigates how behaviour and knowledge may be associated with risk perception.

\section{Methods}

Three Knowledge, Attitudes and Practices (KAP) surveys were carried out in 2014 in Sierra Leone, one of the poorest countries in the world [20]. When the Ebola outbreak started in 2014, the country was still recovering from a long civil war that crippled the country between 1991 and 2002 [20]. A large majority of $80 \%$ of Sierra Leoneans have access to radio, but only $13 \%$ have access to newspapers [21]. Of the total population, $38 \%$ can surf the internet through computers or mobile phones, with up to $65 \%$ in urban areas [22]. The first survey was conducted in August $(n=1413)$ just 3 months into the outbreak and around the time it peaked in the Eastern Province. The second and third surveys were conducted about a month before (October, $n=2086$ ) and a month after (December, $n=3540$ ) the general peak of the outbreak with high transmission occurring in the Northern Province and Western Area. The sampling methods of the KAP surveys have been described in more detail elsewhere [7, 15]. In short, multistage cluster sampling was used, for which the 2004 Sierra Leone Population and Housing Census List of Enumeration Areas served as the sampling frame. In the first KAP survey, 9 out of the 14 districts of Sierra Leone were included, focusing mainly on the districts where Ebola cases were reported at that time. As the virus spread throughout the country, all districts were included in surveys 2 and 3 . Within the randomly selected enumeration areas, the data collector started in the centre of the enumeration area where a pen was dropped. In the direction of the tip of the pen, households were approached based on a predetermined skip interval. In every household, two people were 
interviewed: the head of the household and either a younger person (age 15-24 years) or a woman age 25 or above. All three surveys aimed to produce national and regional-level estimates at a 95\% confidence interval, within a $2.5 \%$ margin of error for national estimates and a $3.5 \%$ margin of error for regional estimates.

The level of risk perception of respondents was measured in the KAP surveys by asking 'what level of risk do you think you have in getting Ebola in the next 6 months?' to which respondents could answer 'no risk, small, moderate or great'. Answers were dichotomised into 'no risk perception' and 'some level of risk perception'.

Exposure to different information sources was ascertained by the question 'Through what means/ways did you learn about Ebola?' This was an open question, where data collectors selected one or more pre-coded options that most closely matched the responses provided. Additional response options were incorporated into the second and third surveys. Mutually exclusive categories were subsequently made by grouping similar information sources into five categories, taking local media landscape into account: electronic media (radio and television), print media (newspapers, brochures and other print materials), new media (mobile phones, text messages, internet), government (house visits by health workers, governments campaigns) and community (religious and traditional leaders, megaphone public announcements, community meetings, friends and relatives). Information sources were also categorized by how many sources someone was exposed to: $0-1$ source, 2,3 and $4-5$ sources. Because sample sizes for 0 and 5 sources were low ( $n=24$ and $n=159$ respectively), they were combined with 1 and 4 sources.

Ebola-specific knowledge was ascertained in the KAP surveys through 2 open-ended and 5 closedended questions (see Table S1 in supplementary file). Two scores were created from this: a knowledge score with a maximum score of 8 points in surveys 1-3 and a misconceptions score, with a maximum score of 12. The scores were dichotomised based on the means [15].

Three Ebola-specific behaviours that are important to transmission control were included in this analysis as outcomes: washing hands with soap and water, avoiding physical contact with people suspected to have Ebola, and avoiding burials that involve contact with the corpse. These behaviours were ascertained through an open question: 'In what ways have you changed your behaviour or took actions to avoid being infected?'

Analyses were adjusted for the following covariates: sex (male, female), age (15-20, 21-35, 36-49, 50+ years), education (no education, primary education, secondary and above), religion (Islam, Christianity) and region (Northern Province, Eastern Province, Southern Province, Western Area).

\section{Statistical analyses}

In an outbreak situation that varies in intensity in different regions at different time points, it is likely that there is a high correlation between time and region. This violates the statistical assumption of independent observations. To account for this, data were analysed using multilevel modelling. In total across the 3 surveys, 167 sampling clusters were used on the first level, after which data were analysed on the individual level. Original survey weights were not applied, as the samples were collected proportionally to the district size in the population and the response rate was $98 \%$. Within the multilevel models, associations were estimated with odds ratios (ORs) and their 95\% confidence intervals (CIs). Four variables had some missing data; age $(n=28)$, education $(n=42)$, religion $(n=24)$ and sex $(n=12)$. Respondents with missing data $(n=104,2 \%$ of the sample) were excluded from the multilevel analyses to allow for complete-case analysis.

Mediation analyses were carried out using the mediated effect model [19] to estimate if knowledge, misconceptions and Ebola-specific behaviours had a mediating effect on risk perception. From the adjusted models, the $\beta$ coefficients for A and B were obtained (see figure S1 in supplementary file), after which they were multiplied. The $x^{2}$ distribution within 1 degree of freedom was used to determine statistical significance of the mediated effect. The analyses were carried out in Stata 15 and $\alpha$ was set to 0.05 for statistical significance.

Ethical permission for the surveys was granted by the Sierra Leone Research and Ethics Review Committee and approved by the Ethical Review Board at Karolinska Institutet in Stockholm, Sweden (dnr 2018/1276-31).

\section{Results}

Pooling data from the three surveys resulted in a total sample size of 7039 respondents. Descriptive statistics of the demographics (Table 1) show that across the four regions in Sierra Leone, around one third of respondents were between 21 and 35 years old. Females comprised $51 \%$ of the total sample. Secondary education was attained by $52 \%$ of respondents, and the highest education attainment was reported from the Western Area (where the capital city Freetown is located), with $68 \%$ of the respondents attaining secondary education or higher levels. Among the four geographic regions, the Northern Province had the largest share of non-educated respondents (38\%). Islam was the most common religious affiliation across the sample $(65 \%)$ and in all regions. Between 50 and $69 \%$ of respondents expressed some level of risk perception during the first survey in the four 
Table 1 Demographic characteristics and risk perception of the pooled sample

\begin{tabular}{|c|c|c|c|c|c|}
\hline & $\begin{array}{l}\text { Western Area } \\
\mathrm{N}(\%)\end{array}$ & $\begin{array}{l}\text { Northern Province } \\
\mathrm{N}(\%)\end{array}$ & $\begin{array}{l}\text { Eastern Province } \\
\mathrm{N}(\%)\end{array}$ & $\begin{array}{l}\text { Southern Province } \\
\mathrm{N}(\%)\end{array}$ & $\begin{array}{l}\text { Total } \\
\text { N (\%) }\end{array}$ \\
\hline \multicolumn{6}{|l|}{ Age (years) } \\
\hline $15-20$ & $388(22)$ & $507(22)$ & $382(24)$ & 319 (24) & $1596(23)$ \\
\hline $21-35$ & $652(37)$ & $745(32)$ & $546(34)$ & $461(34)$ & 2404 (34) \\
\hline $36-49$ & $443(25)$ & $534(23)$ & $370(23)$ & 301 (23) & $1648(24)$ \\
\hline $50+$ & $274(16)$ & $513(22)$ & 307 (19) & $257(19)$ & $1351(19)$ \\
\hline \multicolumn{6}{|l|}{ Sex } \\
\hline Female & $941(53)$ & $1112(48)$ & $838(52)$ & $702(52)$ & $3593(51)$ \\
\hline Male & $821(47)$ & $1200(52)$ & $768(48)$ & 645 (48) & $3434(49)$ \\
\hline \multicolumn{6}{|l|}{ Education } \\
\hline No education & 325 (19) & $877(38)$ & $573(36)$ & $332(25)$ & $2107(30)$ \\
\hline Primary education & $235(13)$ & $355(15)$ & $370(23)$ & $265(20)$ & $1225(18)$ \\
\hline Secondary or higher & $1194(68)$ & $1065(46)$ & $644(41)$ & $742(55)$ & $3665(52)$ \\
\hline \multicolumn{6}{|l|}{ Religion } \\
\hline Islam & $919(52)$ & $1878(81)$ & $1003(62)$ & 778 (58) & $4578(65)$ \\
\hline Christianity & $837(48)$ & $430(19)$ & $603(38)$ & $567(42)$ & $2437(35)$ \\
\hline \multicolumn{6}{|l|}{ Perceived some risk } \\
\hline Survey 1 (Aug 2014) & 235 (55\%) & 302 (69\%) & 135 (50\%) & 166 (60\%) & 838 (59\%) \\
\hline Survey 2 (Oct 2014) & $196(38 \%)$ & $427(68 \%)$ & $124(30 \%)$ & $156(31 \%)$ & $903(43 \%)$ \\
\hline Survey 3 (Dec 2014) & $295(36 \%)$ & $635(51 \%)$ & $408(44 \%)$ & $189(34 \%)$ & $1527(43 \%)$ \\
\hline
\end{tabular}

Missing data

Age: 40 (0.6\%), Sex: 12 (0.2\%), Education: 42 (0.6\%), Religion: 24 (0.3\%)

regions. This decreased during the second survey for all regions apart from the Northern Province.

\section{Demographic determinants of risk perception}

Having secondary school education or higher was positively associated with expressing Ebola risk perception (adjusted OR [AOR] 1.35, 95\% CI 1.14-1.61) compared to having no education. Residing in the Northern Province was strongly associated with expressing Ebola risk perception compared to residing in the Western Area (AOR 2.70, 95\% CI 1.87-3.89). Risk perception was significantly lower in the second survey in October 2014 (AOR 0.40, 95\% CI 0.25-0.64) and third survey in December 2014 (AOR 0.37, 95\% CI 0.25-0.56) compared to the baseline survey in August 2014 (Table 2).

\section{Information sources and risk perception}

In the crude and adjusted models, two information sources had a positive association with expressing risk perception (Table 3): new media (AOR 1.53, 95\% CI 1.21-1.93) and community sources (AOR 1.28, 95\% CI 1.07-1.53). Print media had a borderline positive association with expressing risk perception (AOR 1.24, 95\% CI $1.00-1.54)$. Compared to people who were exposed to none or just one of the information sources, exposure to any three sources was associated with increased risk perception (AOR 1.50, 95\% CI 1.12-2.00). Exposure to four or five sources had an even stronger association (AOR 1.73, 95\% CI 1.18-2.52).

\section{Risk perception and Ebola-specific knowledge and behaviours}

In the fully adjusted models, Ebola-specific knowledge was positively associated with expressing Ebola risk perception (AOR 1.42, 95\% CI 1.15-1.75), see Table 4. Having misconceptions on the other hand was negatively associated with risk perception (AOR 0.67, 95\% CI 0.550.82 ). In terms of behaviours, hand washing had a positive association with risk perception (AOR 1.40, 95\% CI 1.13-1.74) and avoiding burials was negatively associated with risk perception (AOR 0.77, 95\% CI 0.62-0.96). There was no association between avoiding physical contact with Ebola-suspects and risk perception (AOR 1.08, 95\% CI 0.91-1.29).

\section{Mediation analysis}

Knowledge and misconceptions played a mediating role in the association between all information sources (apart from electronic media) and risk perception, see Table 5. Hand washing only mediated the association between government and community sources and risk perception. Whereas there was no direct association between 
Table 2 Association between sociodemographic covariates, level of outbreak and risk perception of getting Ebola

\begin{tabular}{|c|c|c|c|c|c|}
\hline & $\begin{array}{l}\text { Some Risk Perception } \\
\text { N (\%) }\end{array}$ & Crude OR $(95 \% \mathrm{Cl})$ & $P$-value & Adjusted $\mathrm{OR}^{\mathrm{a}}(95 \% \mathrm{Cl})$ & P-value \\
\hline \multicolumn{6}{|l|}{ Age (years) } \\
\hline $15-20$ & $698(44)$ & 1.0 (Reference) & & 1.0 (Reference) & \\
\hline $21-35$ & $1128(47)$ & $1.15(1.01-1.31)$ & 0.039 & $1.24(1.08-1.41)$ & 0.002 \\
\hline $36-49$ & $803(49)$ & $1.20(1.04-1.39)$ & 0.015 & $1.27(1.10-1.48)$ & 0.002 \\
\hline $50+$ & $615(46)$ & $0.99(0.83-1.17)$ & 0.900 & $1.08(0.90-1.31)$ & 0.397 \\
\hline \multicolumn{6}{|l|}{ Sex } \\
\hline Female & $1599(46)$ & 1.0 (Reference) & & 1.0 (Reference) & \\
\hline Male & $1667(49)$ & $1.22(1.09-1.36)$ & 0.001 & $1.17(1.05-1.32)$ & 0.006 \\
\hline \multicolumn{6}{|l|}{ Education } \\
\hline No education & $919(44)$ & 1.0 (Reference) & & 1.0 (Reference) & \\
\hline Primary & $516(42)$ & $1.12(0.92-1.36)$ & 0.251 & $1.14(0.93-1.40)$ & 0.220 \\
\hline Secondary + & $1811(49)$ & $1.42(1.21-1.66)$ & 0.000 & $1.35(1.14-1.61)$ & 0.001 \\
\hline \multicolumn{6}{|l|}{ Religion } \\
\hline Islam & $2138(47)$ & 1.0 (Reference) & & 1.0 (Reference) & \\
\hline Christianity & $1122(46)$ & $1.18(1.03-1.36)$ & 0.019 & $1.15(0.99-1.33)$ & 0.059 \\
\hline \multicolumn{6}{|l|}{ Region } \\
\hline Western & $726(41)$ & 1.0 (Reference) & & 1.0 (Reference) & \\
\hline Northern & $1364(59)$ & $2.28(1.57-3.30)$ & 0.000 & $2.70(1.87-3.89)$ & 0.000 \\
\hline Eastern & $667(41)$ & $1.00(0.64-1.55)$ & 0.999 & $1.15(0.75-1.79)$ & 0.519 \\
\hline Southern & $511(38)$ & $0.75(0.44-1.26)$ & 0.268 & $0.79(0.48-1.31)$ & 0.363 \\
\hline \multicolumn{6}{|l|}{ Survey $1,2,3^{b}$} \\
\hline Survey 1 (Early in the outbreak) & $838(59)$ & 1.0 (Reference) & & 1.0 (Reference) & \\
\hline Survey 2 (Just before the peak of the outbreak) & $903(43)$ & $0.44(0.26-0.74)$ & 0.002 & $0.40(0.25-0.64)$ & 0.000 \\
\hline Survey 3 (Just after the peak of the outbreak) & $1527(43)$ & $0.46(0.30-0.70)$ & 0.000 & $0.37(0.25-0.56)$ & 0.000 \\
\hline
\end{tabular}

adjusted for: age, sex, education, religion, region, KAP survey, all information sources

bSurvey 1: August 2014; Survey 2: October 2014; Survey 3: December 2014

avoiding physical contact with suspected Ebola patients and risk perception (Table 4), this behaviour mediated the association between all information sources apart from electronic media and risk perception.

\section{Discussion}

This study shows that exposure to print media, new media or community-based sources of information was associated with increased risk perception of getting Ebola in the next 6 months from the time of being interviewed. Ebola-specific knowledge and hand washing were positively associated with risk perception, Ebolaspecific misconceptions and avoiding unsafe burials were negatively associated with risk perception. Mediation analyses revealed that knowledge, misconceptions and Ebola-specific behaviours mediated the associations between exposure to various information sources and risk perception.

Whereas risk perception is deemed to be a key determinant to elicit behaviour change, previous studies have shown ambiguous results when testing the role of risk perception in changing the public's behaviour [23-25]. Our findings regarding various behaviours and risk perception similarly go in various directions. Brewer's [19] observation that many studies use cross-sectional surveys to interpret the influence of risk perception on behaviours might explain this inconsistency. As Brewer points out in the 'risk reappraisal hypothesis', over time, and especially in an ever-evolving situation such as the Ebola outbreak, adopted behaviours might in turn influence the level of perceived risk [19]. The observed positive association between hand washing and risk perception can therefore be interpreted in various ways; those who feel at risk are more inclined to wash their hands. Or, those who wash their hands do so for a reason; they felt at risk. Similarly, the negative association between avoiding burials and risk perception can be interpreted in this direction: people who avoided unsafe traditional burials did not perceive themselves to be at risk of getting Ebola. 
Table 3 Association between exposure to information sources and risk perception of getting Ebola

\begin{tabular}{|c|c|c|c|c|c|}
\hline & No (\%) Respondents & Crude OR $(95 \% \mathrm{Cl})$ & $P$-value & Adjusted $\mathrm{OR}^{\mathrm{a}}(95 \% \mathrm{Cl})$ & $P$-value \\
\hline \multicolumn{6}{|c|}{ Electronic media } \\
\hline Yes & $6615(94)$ & $1.10(0.78-1.55)$ & 0.592 & $1.02(0.72-1.44)$ & 0.927 \\
\hline No & $424(6)$ & 1.0 (Reference) & & 1.0 (Reference) & \\
\hline \multicolumn{6}{|c|}{ Print Media } \\
\hline Yes & $679(10)$ & $1.49(1.20-1.85)$ & 0.000 & $1.24(1.00-1.54)$ & 0.046 \\
\hline No & $6360(90)$ & 1.0 (Reference) & & 1.0 (Reference) & \\
\hline \multicolumn{6}{|c|}{ New Media } \\
\hline Yes & $1012(14)$ & $1.69(1.33-2.13)$ & 0.000 & $1.53(1.21-1.93)$ & 0.000 \\
\hline No & $6027(86)$ & 1.0 (Reference) & & 1.0 (Reference) & \\
\hline \multicolumn{6}{|c|}{ Government } \\
\hline Yes & $3206(46)$ & $1.07(0.84-1.36)$ & 0.584 & $1.01(0.80-1.27)$ & 0.958 \\
\hline No & $3833(54)$ & 1.0 (Reference) & & 1.0 (Reference & \\
\hline \multicolumn{6}{|c|}{ Community } \\
\hline Yes & $4133(59)$ & $1.34(1.11-1.60)$ & 0.002 & $1.28(1.07-1.53)$ & 0.008 \\
\hline No & $2906(41)$ & 1.0 (Reference) & & 1.0 (Reference & \\
\hline \multicolumn{6}{|c|}{ No. Exposures ${ }^{b}$} \\
\hline $0-1$ & $1916(27)$ & 1.0 (Reference) & & 1.0 (Reference) & \\
\hline 2 & $2450(35)$ & $1.18(0.96-1.46)$ & 0.118 & $1.18(0.95-1.46)$ & 0.132 \\
\hline 3 & $1998(28)$ & $1.56(1.17-2.07)$ & 0.003 & $1.50(1.12-2.00)$ & 0.006 \\
\hline $4-5$ & $675(10)$ & $1.83(1.25-2.67)$ & 0.002 & $1.72(1.17-2.51)$ & 0.006 \\
\hline
\end{tabular}

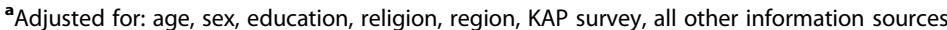

${ }^{\text {b}}$ Adjusted model includes: age, sex, education, religion, region, KAP survey

Table 4 Association between knowledge, misconceptions, behaviours and risk perception of getting Ebola

\begin{tabular}{|c|c|c|c|c|c|c|}
\hline & Crude OR $(95 \% \mathrm{Cl})$ & $P$-value & Adjusted OR ${ }^{\mathrm{a}}(95 \% \mathrm{Cl})$ & $P$-value & Adjusted $\mathrm{OR}^{\mathrm{b}}(95 \% \mathrm{Cl})$ & $P$-value \\
\hline \multicolumn{7}{|c|}{ Knowledge } \\
\hline No & 1.0 (Reference) & & 1.0 (Reference) & & 1.0 (Reference) & \\
\hline Yes & $1.50(1.21-1.86)$ & 0.000 & $1.46(1.17-1.81)$ & 0.001 & $1.42(1.15-1.75)$ & 0.001 \\
\hline \multicolumn{7}{|c|}{ Misconceptions } \\
\hline No & 1.0 (Reference) & & 1.0 (Reference) & & 1.0 (Reference) & \\
\hline Yes & $0.66(0.54-0.80)$ & 0.000 & $0.69(0.56-0.83)$ & 0.000 & $0.67(0.55-0.82)$ & 0.000 \\
\hline \multicolumn{7}{|c|}{ Hand washing } \\
\hline No & 1.0 (Reference) & & 1.0 (Reference) & & 1.0 (Reference) & \\
\hline Yes & $1.45(1.17-1.81)$ & 0.001 & $1.45(1.16-1.81)$ & 0.000 & $1.40(1.13-1.74)$ & 0.002 \\
\hline \multicolumn{7}{|c|}{ Avoid physical contact } \\
\hline No & 1.0 (Reference) & & 1.0 (Reference) & & 1.0 (Reference) & \\
\hline Yes & $1.17(0.97-1.40)$ & 0.094 & $1.13(0.95-1.35)$ & 0.178 & $1.08(0.91-1.29)$ & 0.380 \\
\hline \multicolumn{7}{|c|}{ Avoid burials } \\
\hline No & 1.0 (Reference) & & 1.0 (Reference) & & 1.0 (Reference) & \\
\hline Yes & $0.81(0.66-1.01)$ & 0.059 & $0.80(0.64-0.99)$ & 0.043 & $0.77(0.62-0.96)$ & 0.023 \\
\hline
\end{tabular}

${ }^{a}$ Adjusted for: region, sex, age, religion, education, KAP survey

${ }^{\mathbf{b}}$ Adjusted for: region, sex, age, religion, education, KAP survey and all information sources 
Table 5 Mediation analyses

\begin{tabular}{|c|c|c|c|c|}
\hline Category & Beta A (SE) & Beta B (SE) & Beta AB (SE) & $P$-value \\
\hline \multicolumn{5}{|c|}{ Knowledge to risk perception of getting Ebola } \\
\hline Electronic media & $0.656(0.115)$ & $0.350(0.108)$ & $0.230(0.082)$ & 0.185 \\
\hline Print media & $0.216(0.108)$ & $0.350(0.108)$ & $0.076(0.044)$ & 0.015 \\
\hline New media & $0.344(0.117)$ & $0.350(0.108)$ & $0.120(0.055)$ & 0.050 \\
\hline Government & $0.388(0.092)$ & $0.350(0.108)$ & $0.136(0.053)$ & 0.041 \\
\hline Community & $0.307(0.086)$ & $0.350(0.108)$ & $0.107(0.045)$ & 0.016 \\
\hline 2 sources & $0.197(0.096)$ & $0.342(0.107)$ & $0.068(0.039)$ & 0.006 \\
\hline 3 sources & $0.603(0.115)$ & $0.342(0.107)$ & $0.207(0.076)$ & 0.157 \\
\hline $4-5$ sources & $1.237(0.186)$ & $0.342(0.107)$ & $0.424(0.147)$ & 0.466 \\
\hline \multicolumn{5}{|c|}{ Misconceptions to risk perception of getting Ebola } \\
\hline Electronic media & $0.082(0.150)$ & $-0.398(0.101)$ & $-0.033(0.060)$ & 0.094 \\
\hline Print media & $0.056(0.128)$ & $-0.398(0.101)$ & $-0.022(0.051)$ & 0.049 \\
\hline New media & $0.147(0.119)$ & $-0.398(0.101)$ & $-0.059(0.050)$ & 0.042 \\
\hline Government & $0.218(0.099)$ & $-0.398(0.101)$ & $-0.087(0.045)$ & 0.025 \\
\hline Community & $0.174(0.101)$ & $-0.398(0.101)$ & $-0.069(0.044)$ & 0.021 \\
\hline 2 sources & $-0.019(0.106)$ & $-0.401(0.100)$ & $0.008(0.043)$ & 0.019 \\
\hline 3 sources & $0.341(0.129)$ & $-0.401(0.100)$ & $-0.137(0.062)$ & 0.107 \\
\hline $4-5$ sources & $0.430(0.189)$ & $-0.401(0.100)$ & $-0.172(0.087)$ & 0.251 \\
\hline \multicolumn{5}{|c|}{ Hand washing to risk perception of getting Ebola } \\
\hline Electronic media & $0.357(0.156)$ & $0.338(0.109)$ & $0.121(0.066)$ & 0.096 \\
\hline Print media & $0.241(0.157)$ & $0.338(0.109)$ & $0.082(0.059)$ & 0.066 \\
\hline New media & $0.313(0.142)$ & $0.338(0.109)$ & $0.106(0.059)$ & 0.064 \\
\hline Government & $0.282(0.104)$ & $0.338(0.109)$ & $0.096(0.047)$ & 0.020 \\
\hline Community & $0.328(0.080)$ & $0.338(0.109)$ & $0.111(0.045)$ & 0.015 \\
\hline 2 sources & $0.329(0.089)$ & $0.337(0.109)$ & $0.111(0.047)$ & 0.020 \\
\hline 3 sources & $0.638(0.124)$ & $0.337(0.109)$ & $0.215(0.081)$ & 0.178 \\
\hline $4-5$ sources & $0.915(0.227)$ & $0.337(0.109)$ & $0.308(0.126)$ & 0.385 \\
\hline \multicolumn{5}{|c|}{ Avoiding physical contact to risk perception of getting Ebola } \\
\hline Electronic media & $0.534(0.169)$ & $0.078(0.088)$ & $0.041(0.049)$ & 0.071 \\
\hline Print media & $0.411(0.106)$ & $0.078(0.088)$ & $0.032(0.037)$ & 0.018 \\
\hline New media & $0.459(0.108)$ & $0.078(0.088)$ & $0.036(0.041)$ & 0.033 \\
\hline Government & $0.369(0.080)$ & $0.078(0.088)$ & $0.029(0.033)$ & 0.008 \\
\hline Community & $0.255(0.081)$ & $0.078(0.088)$ & $0.020(0.023)$ & 0.000 \\
\hline 2 sources & $0.191(0.103)$ & $0.079(0.088)$ & $0.015(0.019)$ & 0.000 \\
\hline 3 sources & $0.666(0.120)$ & 0.079 (0.088) & $0.042(0.060)$ & 0.138 \\
\hline 4-5 sources & $1.132(0.165)$ & $0.079(0.088)$ & $0.089(0.101)$ & 0.381 \\
\hline \multicolumn{5}{|c|}{ Avoiding unsafe burial to risk perception of getting Ebola } \\
\hline Electronic media & $0.565(0.209)$ & $-0.255(0.111)$ & $-0.144(0.082)$ & 0.178 \\
\hline Print media & $0.609(0.133)$ & $-0.255(0.111)$ & $-0.156(0.076)$ & 0.143 \\
\hline New media & $0.297(0.103)$ & $-0.255(0.111)$ & $-0.076(0.042)$ & 0.009 \\
\hline Government & $0.225(0.106)$ & $-0.255(0.111)$ & $-0.057(0.037)$ & 0.003 \\
\hline Community & $0.432(0.097)$ & $-0.255(0.111)$ & $-0.110(0.054)$ & 0.040 \\
\hline
\end{tabular}


Table 5 Mediation analyses (Continued)

\begin{tabular}{lllll}
\hline Category & Beta A (SE) & Beta B (SE) & Beta AB (SE) & $P$-value \\
\hline 2 sources & $0.182(0.133)$ & $-0.249(0.110)$ & $-0.045(0.039)$ & 0.004 \\
3 sources & $0.630(0.158)$ & $-0.249(0.110)$ & $-0.157(0.080)$ & 0.167 \\
$4-5$ sources & $1.178(0.220)$ & $-0.249(0.110)$ & $-0.293(0.141)$ & 0.434 \\
\hline
\end{tabular}

Ideally, temporal data is used to test this hypothesis [19]. Our data, while collected at three progressive time periods that aligned with different stages of the outbreak, is considered cross-sectional data. However, our results show that over time, overall risk perception decreased compared to the first survey in August 2014. This is in line with the actual risk of transmission over time and might indicate that by adopting protective behaviours, the perception of risk was lowered over the course of the outbreak - supporting the risk reappraisal hypothesis.

Risk perception has been described to have two components: a subjective component based on feelings and an analytical component based on available facts [26]. Whereas in theory the analytical component should make calculations based on actual risk, it has been shown that people are relatively insensitive to understanding probability. The subjective component will often take over, whereby feelings determine the level of perceived risk [26]. The finding that risk perception decreased over time, might therefore point to successes in risk communication to match the public's subjective risk to the actual risk of transmission. However, as many other interventions were implemented concurrently, we cannot discern the size of the effect of any risk communication intervention using an observational design. Furthermore, social learning may have occurred intrinsically without external interventions. For instance, when people observed fewer cases of Ebola in their communities, districts, and country, they might have felt less at risk of getting Ebola. Therefore, intrinsic social learning may also contribute in explaining why risk perceptions declined sharply between the first survey (administered before the peak of the outbreak) and third survey (administered after the peak).

Exposure to community-based information sources through community leaders, community meetings and friends and relatives was associated with expressing Ebola risk perception. Together, these community-based sources form a group of people who are highly trusted and respected [27]. Whereas the initial response to the outbreak was criticized for prioritizing top-down risk communication messaging instead of focussing on community engagement, local leaders were actively engaged later in the outbreak response [28]. Community sources and new media are comparable in that they both facilitate active interaction between the messenger and the recipient of that message [27]. As opposed to top-down messaging, this form of two-way communication allows recipients to ask questions, express concerns and discuss solutions [29]. It is plausible that by potentially getting a better understanding of the disease and the outbreak through these interactions, the perception of risk might have been enhanced.

Having Ebola-specific knowledge was also positively associated with risk perception. It is plausible that people with enhanced risk perception sought more knowledge, even though with this study design it is equally possible that people with increased knowledge may have elevated risk perception. However, an online survey in the USA found that higher knowledge was associated with decreased perceptions of risk about Ebola [30]. In another online survey in Germany, there was no association between Ebola-specific knowledge and being worried about Ebola [5]. The closeness and actual immediate risk in Sierra Leone, and the accuracy of risk perceptions might have played a role in this [16]. It is also possible that a combination of the directions of the association occurred. However, with the available data we cannot discern this. Finally, having misconceptions about Ebola was negatively associated with perceiving some level of risk. This is an important finding, as misconceptions can also be associated with risk behaviour [15]. A survey from the North Kivu and Ituri Ebola outbreak in the Democratic Republic of the Congo shows that belief in misinformation was associated with a decreased likelihood of adopting protective behaviours [31].

\section{Strengths and limitations}

A major strength of this study was the relatively large sample sizes of the three KAP surveys. The surveys captured population-level data during an ongoing largescale outbreak at several timepoints across all geographic regions of Sierra Leone. The sampling method and the high response rates should mitigate the risk of selection bias. The KAP survey instruments were not validated because of the ongoing emergency and the need of gathering data rapidly. However, the survey instruments were pilot-tested and KAP surveys have shown to be a useful tool in several outbreaks $[7,8,31,32]$. Risk perception was measured using a generic unidimensional Likertitem in the three KAP surveys that our analyses are based on. Models and theories of risk perception and 
behavioural change assert that risk perception is a complex phenomenon that is driven by the multiplicity of affective responses to the hazard, subjective appraisals of its likelihood, and perceptions of its consequences [33]. Given the multidimensionality of risk perception, future Ebola (or similar epidemic) risk perception assessments should consider including multiple items that reflect the underlying domains of risk perception such as affect, probability, and consequence [16].

Exposure to information sources was dichotomised into exposed and unexposed. We did not have information on the content of the messaging, the framing, the tone or the amount of actual coverage. These factors can all potentially play a role in amplifying or attenuating the perceived risk - especially in a fluid and chaotic outbreak context [34]. Moreover, we carried out mediation analyses with cross-sectional data, and therefore cannot establish if the assumed exposure to information sources happened before the assumed mediators (knowledge, misconceptions, and behaviour) and outcome (risk perception). However, it is plausible that the public in Sierra Leone first learned about the existence of an outbreak through at least one of the information sources we included in this study.

We attempted to account for the high correlation between time and region by applying multilevel modelling. Whereas we adjusted for several demographic factors, unmeasured, residual confounding could have had an influence on the outcomes. The three surveys covered all 4 regions in Sierra Leone, but contrary to survey 2 and 3 , survey 1 only covered 9 out of 14 districts. To mitigate this limitation, the multilevel approach accounted for the effects of geographic clusters - which were more granular than districts.

\section{Conclusion}

Our results provide novel insights into the complex relationship between risk perception and human behaviour during an unprecedented Ebola outbreak. Exposure to community-level information sources was positively associated with perceiving some Ebola risk. More people perceived themselves to be at risk before the peak of the outbreak compared to after the peak. Individuals who said they took protective actions against Ebola perceived themselves to be at decreased risk of getting Ebola. These findings reinforce the importance of effective risk communication, especially in the early stages of an outbreak, to help the public understand their risk and take appropriate actions to reduce their acquisition risk. Community-level information sources may help to align the public's perceived risk with their actual epidemiological risk through continuous exchange of information that help to improve knowledge, reduce misconceptions, and facilitate uptake of protective behaviours. As part of global health security efforts, increased investments are needed for community-level engagements that allow for two-way communication during health emergencies.

\section{Supplementary information}

Supplementary information accompanies this paper at https://doi.org/10. 1186/s12889-020-09648-8.

Additional file 1 : Table S1. Composite variables for Ebola-specific knowledge and misconceptions. Figure S1. Mediation analysis among information exposure, knowledge, behaviour and risk perception, Sierra Leone, 2014

\section{Abbreviations}

AOR: Adjusted odds ratio; Cl : Confidence interval; KAP : Knowledge, attitudes, practices; OR : Odds ratio; SE : Standard error

\section{Acknowledgements}

We would like to thank the respondents of the surveys for their time, and the data collectors for carrying out this important work during a health emergency.

\section{Authors' contributions}

MFJ, PS, MBJ contributed to the study design and the data collection. MW, MFJ, ZZ, HN contributed to the analysis plan for this study. MW, MFJ, PS, ZZ, $\mathrm{HN}$ contributed to the data management and statistical analysis. MW, MFJ, HN contributed to writing the manuscript. All authors read and approved the final manuscript.

\section{Funding}

This study was funded by the CDC Foundation and the Swedish Research Council (Vetenskapsrådet: 2017-05581). The funders had no role in the study design, data collection and analysis, decision to publish, or preparation of the manuscript. The corresponding author had full access to all the data in the study and had final responsibility for the decision to submit for publication. Open Access funding provided by Karolinska Institute.

\section{Availability of data and materials}

The datasets used and/or analysed during the current study are available from the corresponding author on reasonable request.

\section{Ethics approval and consent to participate}

Ethical permission for the surveys was granted by the Sierra Leone Research and Ethics Review Committee and approved by the Ethical Review Board at Karolinska Institutet in Stockholm, Sweden (dnr 2018/1276-31). Written consent was obtained from study participants before the start of the survey. For participants under 16 years of age, written consent was obtained from a parent or guardian (the head of the household).

\section{Consent for publication}

Not applicable.

\section{Competing interests}

The authors declare no conflict of interest.

\section{Author details}

${ }^{1}$ Department of Global Public Health, Karolinska Institutet, Tomtebodavägen 18A, 17717 Stockholm, Sweden. ${ }^{2}$ Centers for Disease Control and Prevention, Atlanta, GA, USA. ${ }^{3}$ FOCUS1000, Freetown, Sierra Leone. ${ }^{4}$ Jönköping

International Business School, Jönköping, Sweden.

Received: 7 May 2020 Accepted: 6 October 2020

Published online: 12 October 2020

\section{References}

1. World Health Organization. Ground zero in Guinea: the Ebola outbreak smoulders - undetected - for more than 3 months. Available from: https://www. who.int/csr/disease/ebola/ebola-6-months/guinea/en/. [cited 2019 Apr 1]. 
2. Centers for Disease Control and Prevention. 2014-2016 Ebola Outbreak in West Africa. 2019. Available from: https://www.cdc.gov/vhf/ebola/history/2 014-2016-outbreak/index.html. [cited 2019 Mar 1].

3. World Health Organization. Ebola Situation Report 2016. Available from: http://apps.who.int/iris/bitstream/10665/205945/1/ebolasitrep_5may2016_ eng.pdf?ua=1.

4. Gesser-edelsburg A, Shir-Raz Y, Hayek S, Lev OS. What does the public know about Ebola? The public's risk perceptions regarding the current Ebola outbreak in an as-yet unaffected country. Am J Infect Control. 2015;43(7): 669-75. https://doi.org/10.1016/j.ajic.2015.03.005.

5. Rübsamen N, Castell S, Horn J, Karch A, Ott JJ, Raupach-Rosin H, et al. Ebola risk perception in Germany, 2014. Emerg Infect Dis. 2015;21(6):1012-8.

6. Tenkorang EY. Ebola-related stigma in Ghana: Individual and community level determinants. Soc Sci Med. 2017;182:142-9. https://doi.org/10.1016/j. socscimed.2017.03.060

7. Jalloh MF, Sengeh P, Monasch R, Jalloh MB, DeLuca N, Dyson M, et al. National survey of Ebola-related knowledge, attitudes and practices before the outbreak peak in Sierra Leone: August 2014. BMJ Glob Heal. 2017;2(4): e000285. https://doi.org/10.1136/bmjgh-2017-000285.

8. Jiang H, Shi G-Q, Tu W-X, Zheng C-J, Lai X-H, Li X-X, et al. Rapid assessment of knowledge, attitudes, practices, and risk perception related to the prevention and control of Ebola virus disease in three communities of Sierra Leone. Infect Dis Poverty. 2016;5(53):1-6. https://doi.org/10.1186/s40249016-0142-9

9. Paek H-J, Hove T. Risk Perceptions and Risk Characteristics. Oxford Res Encycl Commun. 2017 1-16.

10. Slovic P. Perception of Risk. Science. 1987;236:280-5.

11. Sell TK, Boddie C, Mcginty EE, Pollack K, Smith KC, Burke TA, et al. Media messages and perception of risk for Ebola virus infection, United States. Emerg Infect Dis. 2017;23(1):108-11.

12. Kasperson R, Renn O, Slovic P, Brown H, Emel J, Goble R, Kasperson J, Ratick S. The social amplification of risk: a conceptual framework. Risk Anal. 1988; 8(2):177-87.

13. Funk S, Ciglenecki I, Tiffany A, Gignoux E, Camacho A, Eggo RM, et al. The impact of control strategies and behavioural changes on the elimination of Ebola from Lofa County, Liberia. 2017; .

14. Caleo G, Duncombe J, Jephcott F, Lokuge K, Mills C, Looijen E, et al. The factors affecting household transmission dynamics and community compliance with Ebola control measures: a mixed-methods study in a rural village in Sierra Leone. BMC Public Health. 2018;18(248):1-13.

15. Winters $M$, Jalloh MF, Sengeh $P$, Jalloh MB, Conteh $L$, Bunnell $R$, et al. Risk Communication and Ebola-Specific Knowledge and Behavior during 20142015 Outbreak, Sierra Leone. Emerg Infect Dis. 2018;24(2):336-44.

16. Ferrer R, Klein WM. Risk perceptions and health behavior. Curr Opin Psychol. 2015;5:85-9.

17. World Health Organization. Communicating Risk in Public Health Emergencies 2018. Available from: http://www.who.int/risk-communication/ guidance/download/en/

18. Glanz K, Rimer B, Viswanath K. Health behaviour and health education: theory, research, and practice. San Fransisco: Jossey-Bass; 2008. p. 45-51.

19. Brewer NT, Weinstein ND, Cuite CL, Herrington JE. Risk perceptions and their relation to risk behavior. Ann Behav Med. 2004;27(2):125-30.

20. Marshall K. Roles of religious actors in the west African Ebola response. Dev Pract. 2017;27(5):622-33. https://doi.org/10.1080/09614524.2017.1327573.

21. Wittels A, Maybank N. Communication in Sierra Leone: an analysis of media and Mobile audiences 2016. Available from: www.soapbox.co.uk.

22. Statistics Sierra Leone, Oxford Poverty and Human Development Initiative, United Nations Development Programme. Sierra Leone Multidimensional Poverty Index 2019. Freetown; 2019

23. Adedimeji AA, Omololu FO, Odutolu O. HIV risk perception and constraints to protective behaviour among young slum dwellers in Ibadan, Nigeria. J Heal Popul Nutr. 2007;25(2):146-57.

24. Gerrard M, Gibbons FX, Bushman BJ. Relation between perceived vulnerability to HIV and precautionary sexual behavior. Psychol Bull. 1996; 119(3):390-409.

25. Van der Pligt J. Perceived risk and vulnerability as predictors of precautionary behaviour. Br J Health Psychol. 1998;3:1-14.

26. Slovic P, Finucane ML, Peters E, MacGregor DG. Risk as analysis and risk as feelings. Risk Anal. 2004;24(2):1-12 Available from: http://www. trendfollowing.com/whitepaper/dr502.pdf.
27. Gillespie AM, Obregon R, Asawi RE, Richey C, Manoncourt E, Joshi K, et al. Social mobilization and community engagement central to the Ebola response in West Africa: lessons for future public health emergencies. Glob Heal Sci Pract. 2016;4(4):626-46.

28. Marais F, Minkler M, Gibson N, Mwau B, Mehtar S, Ogunsola F, et al. A community-engaged infection prevention and control approach to Ebola. Health Promot Int 2015; 1-10. Available from: http://www.ncbi.nlm.nih.gov/ pubmed/25680362.

29. Toppenberg-Pejcic D, Noyes J, Allen T, Alexander N, Vanderford M, Gamhewage G. Emergency risk communication: lessons learned from a rapid review of recent gray literature on Ebola, Zika, and yellow fever. Health Commun 2019;34(4):437-455. do: https://doi.org/10.1080/10410236. 2017.1405488.

30. Rolison JJ, Hanoch Y. Knowledge and risk perceptions of the Ebola virus in the United States. Prev Med Reports. 2015;2:262-4. https://doi.org/10.1016/j. pmedr.2015.04.005.

31. Vinck P, Pham PN, Bindu KK, Bedford J, Nilles EJ. Institutional trust and misinformation in the response to the 2018-19 Ebola outbreak in North Kivu, DR Congo: a population-based survey. Lancet Infect Dis 2019; 3099(19):1-8. doi: https://doi.org/10.1016/S1473-3099(19)30063-5.

32. Claude KM, Underschultz J, Hawkes MT. Ebola virus epidemic in war-torn eastern DR Congo. Lancet. 2018;392(18):1399-401 Available from: https:// linkinghub.elsevier.com/retrieve/pii/S014067361832419X.

33. Wilson RS, Zwickle A. Developing a Broadly Applicable Measure of Risk Perception. Risk Anal. 2018 1-15.

34. Mccarthy M, Brennan M, De Boer M, Ritson C. Media risk communication what was said by whom and how was it interpreted. J Risk Res. 2008;11(3): 375-94.

\section{Publisher's Note}

Springer Nature remains neutral with regard to jurisdictional claims in published maps and institutional affiliations.

Ready to submit your research? Choose BMC and benefit from:

- fast, convenient online submission

- thorough peer review by experienced researchers in your field

- rapid publication on acceptance

- support for research data, including large and complex data types

- gold Open Access which fosters wider collaboration and increased citations

- maximum visibility for your research: over $100 \mathrm{M}$ website views per year

At $\mathrm{BMC}$, research is always in progress.

Learn more biomedcentral.com/submissions 